ISSN: 2354 - 1431

http://tckh.daihoctantrao.edu.vn/

\title{
Nghiên cứu tính chất đất dốc tại huyện Phú Lương tỉnh Thái Nguyên
}

\author{
Đàm Xuân Vận ${ }^{a,}$ Ông Á Huân ${ }^{a}$, Trần Thị Phảa ${ }^{a}$, Nguyễn Văn Giáp ${ }^{b,{ }^{*}}$, Duong Thị Minh Hòa ${ }^{a}$ \\ ${ }^{a}$ Truòng Đại học Nông Lâm Thái Nguyên \\ ${ }^{b}$ Truòng Đại học Tân Trào \\ *Email: giapvannguyen@gmail.com
}

\section{Article info}

Recieved:

05/7/2017

Accepted:

03/8/2017

\section{Keywords:}

Sloping land;Phu luong district; NDVI.

\begin{abstract}
Study on sloping land propertiesin Phu Luong District shows that the soil environment is influenced by two main factors: climate and human resources. The influence of rainfall on vegetation (NDVI index) affects the distribution of plants. At different slopping gradients, there are different NDVI index and different types of vegetation at different slopes have different soil properties. The soil has a high level of sour to medium sour, total nitrogen content and total humus levels are poor to medium, low $\mathrm{K}_{2} \mathrm{O}$ content, low $\mathrm{P}_{2} \mathrm{O} 5$ content, $\mathrm{Ca}^{2+}$ exchanged in the soil in low to medium, the content of $\mathrm{Mg}^{2+}$ exchange rate is very low to low, heavy metal contents $(\mathrm{As}, \mathrm{Pb}, \mathrm{Cd})$ are lower than Vietnamese standard regulation (QCVN 03-MT). On rice growing land and tea have a higher heavy metal contents than forest plants such as acacia. Residue levels of plant protection chemicals have not been detected.
\end{abstract}

\section{I. Đặt vấn đề}

Phú Lương là huyện miền núi nằm ở phía Bắc tỉnh Thái Nguyên, diện tích vùng đồi núi chiếm $70 \%$ diện tích toàn huyện, địa hình cao, chia cắt phức tạp do quá trình Castơ phát triển mạnh, độ cao trung bình so với mặt nước biển từ $100 \mathrm{~m}$ đến $400 \mathrm{~m}$. Các xã ở vùng bắc và tây bắc huyện có nhiều núi cao, độ cao trung bình từ $300 \mathrm{~m}$ đến $400 \mathrm{~m}$, độ dốc phần lớn trên 200 , thảm thực vật dầy, độ che phủ cao chiếm chủ yếu là rừng thường xanh.Các xã ở vùng phía nam huyện địa hình bằng phẳng hơn,có nhiều đồi và núi thấp. Độ cao trung bình từ $100-300 \mathrm{~m}$, độ dốc thường dưới 150 , tương đối thuận tiện cho sản xuất nông nghiệp. Các vấn đềvề canh tác và các yếu tố tài nguyên khí hậu luôn đe dọa thường xuyên đối với đất dốc trên địa bàn huyện, gây nên sự mất dinh dưỡng và độ phì của lớp đất mặt. Bên cạnh đó các câu hỏi được quan tâm nhu: canh tác nông nghiệp, sử dụng phân bón, thuốc bảo vệ thực vật của người dân liệu dẫn đến thay đổi tính chất, môi trường đất dốc hay không được đặt ra.

\section{II. Đối tượng và phương pháp nghiên cứu}

\section{1. Đối tượng và vật liệu nghiên cứu}

- Đối tuợng nghiên cứu:

+ Độ dốc

+ Chỉ số thực vật (NDVI)

+ Chỉ số khí hậu lượng mưa

+ Nhu cầu sử dụng đất
+ Một số tính chất môi trường đất dốc.

+ Sử dụng là ảnh landsat 8 và dữ liệu mô hình số độ cao DEM với độ phân giải $30 \times 30 \mathrm{~m}$, ảnh được chụp tháng 6 năm 2016 từ nguồn htt://earthexplorer.usgs.gov. Biên tập và xây dựng bản đồ bằng phần mềm ArcGIS 10.2.

\subsection{Phưong pháp nghiên cúu}

- Phương pháp phân tích các yếu tố tác động:

+ Phương pháp xác định độ dốc

Độ dốc được xác định từ mô hình số độ cao (DEM) trong ArcGIS 10.2.Được chia thành các cấp độ dốc sau:

+ Cấp 1: từ $0^{0}-3^{0} ; \quad \quad+$ Cấp 4: từ $15^{0}-20^{\circ}$;

+ Cấp 2: từ $3^{0}-8^{0} ; \quad+$ Cấp 5: từ $20^{\circ}-25^{\circ}$;

+ Cấp 3: từ $8^{0}-15^{\circ}$; $\quad$ Cấp 6: từ $>25^{\circ}$.

+ Phương pháp xác yếu tố lượng mưa trung bình năm

Bản đồ lượng mưa được xây dựng dựa vào số liệu lượng mưa trung bình năm của các trạm đo mưa bằng phương pháp nội suy không gian trên phần mềm ArcGIS 10.2

+ Phương pháp xác định chỉ số thực vật

Chỉ số khác biệt thực vật NDVI (Normalized Difference Vegetation Index) được xác định bằng công thức sau:

$$
\text { NDVI }=\frac{(\text { NIR }}{\text { RED })}
$$




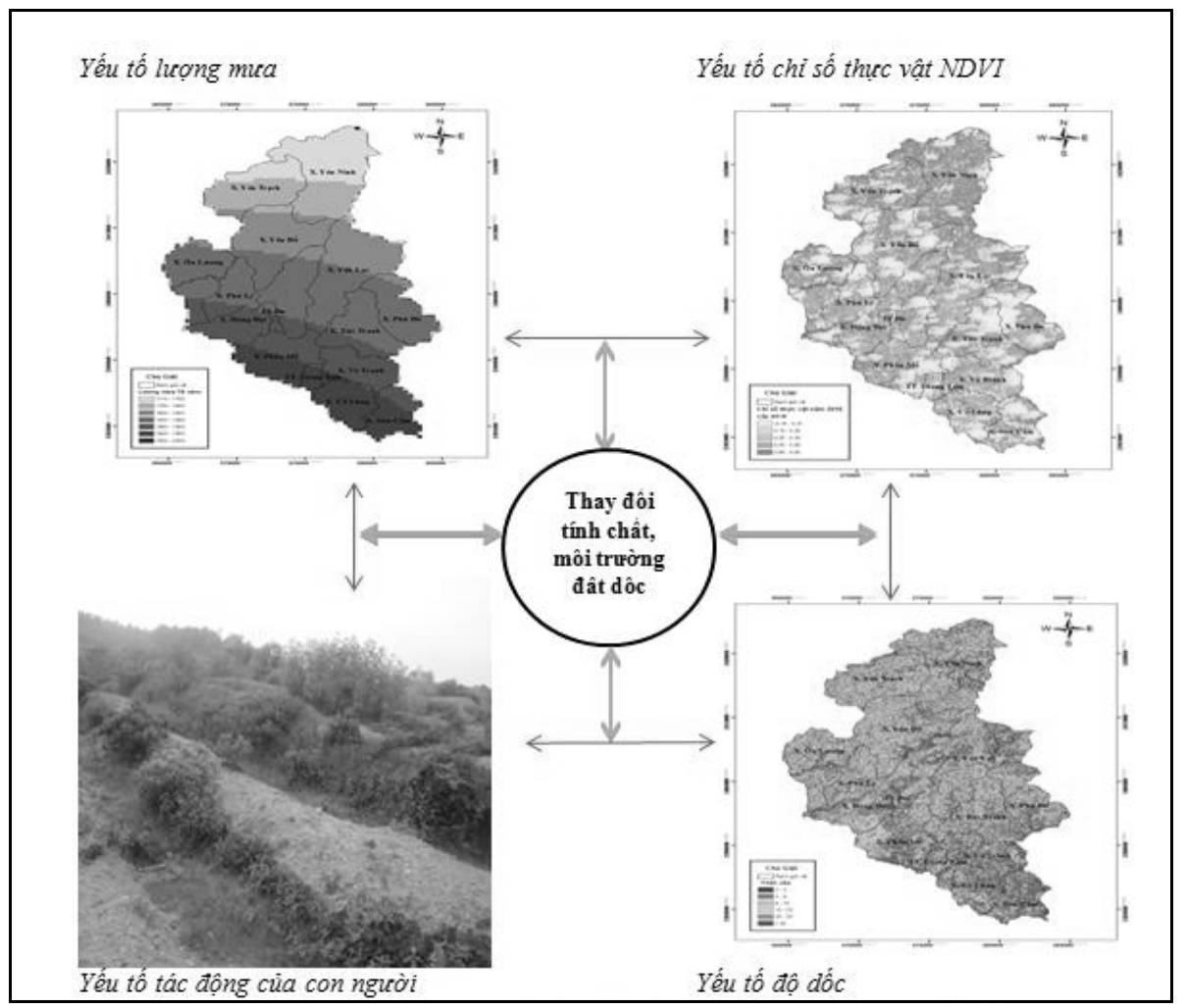

Hình 1: Mối quan hệ tác động đến tính chất môi truờng đất dốc

Trong đó: NIR, RED lần lượt là giá trị phản xạ phổ kênh cận hồng ngoại và kênh đỏ

NDVI có giá trị trong khoảng $-1 \leq \mathrm{I} \leq+1$; trường hợp cần tổ hợp hoặc tính toán với các kênh khác, giá trị của NDVI có thể được chuyển thành 256 giá trị ( 8 bit).

- Phuoong pháp lấy mẫu đất và phân tích mẫu:

+ Vị trí lấy mẫu đất trên địa bàn đất dốc huyện Phú Lương, tại các xã: Động Đạt, Yên Lạc, Yên Ninh. Mẫu đất được lấy đại diện theo độ dốc và theo loại đất.

+ Phương pháp phân tích mẫu đất được phân tích theo tiêu chuẩn Việt Nam hiện hành

Chỉ tiêu phân tích gồm: $\mathrm{pH}$, Đạm tổng số, Mùn tổng số (\%OM), $\mathrm{K}_{2} \mathrm{O}$ dễ tiêu, $\mathrm{P}_{2} \mathrm{O}_{5}$ dễ tiêu, $\mathrm{Ca}^{2+}, \mathrm{Mg}^{2+}$, kim loại năng ( $\mathrm{As}, \mathrm{Pb}, \mathrm{Cd})$, hóa chất BVTV.

- Phuoong pháp điều tra thực địa

+ Điều tra, đối soát, bổ sung, chỉnh lý các yếu tố nội dung cơ sở địa lý trên bản đồ;

+ Điều tra, kiểm tra, đối soát kết quả để đối chứng những thông tin giải đoán ảnh.

- Phuơng pháp xủ lý số liệu

Số liệu được tổng hợpbằng phần mềm Excel 2010.

- Phưong pháp so sánh

So sánh kết quả phân tích mẫu đất với các thang tiêu chuẩn, quy chuẩn Việt Nam hiện hành.

\section{Kết quả và thảo luận}

3.1. Xác định yếu tố tác động đến tính chất, môi trường đất dốc
Qua kết quả nghiên cứu thì tính chất cơ bản của môi trường đất dốc thay đổi dựa vào hai nhóm yếu tố chính đó là yếu tố tài nguyên sinh khí hậu như: yếu tố khí hậu (lượng mưa), yếu tố thảm thực vật (chỉ số NDVI), yếu tố địa hình (độ dốc) và yếu tố đặc biệt là con người. Hai yếu tố này đều có tác động hai chiều và quan hệ với nhau. Yếu tố tự nhiên là yếu tố bồi dưỡng tính chất môi trường đất nhưng cũng là yếu tố tác động ngược lại theo quy luật tuần hoàn. (Hình 1)

\subsection{Phân tích đối tượng tác động của tài nguyên sinh khí hậu}

\subsubsection{Tác động giữa luọng mua (LM) đến chỉ số thụcc vật (NDVI) tại huyện Phú Luơng (Bảng 1)}

Căn cứ vào hình 1 và bảng 1 cho thấykhu vực lượng mưa trung bình năm ở $1880 \mathrm{~mm} /$ năm có diện tích chiếm $32,51 \%$, với 11954,73 ha, giá trị $\mathrm{NDVI}=0,6$; ở lượng mưa này cũng cao nhất có diện tích là 7387,83 ha trên diện tích 24726,66 ha (67,23\%). Trong đó lượng mưa trung bình năm có từ $1750 \mathrm{~mm} /$ năm đến $1820 \mathrm{~mm} /$ năm đạt 13936,21 ha chiếm 35,44\%,và giá trị NDVI tăng dần theo lượng mưa. Tại các lượng mưa trung bình năm từ $1920 \mathrm{~mm} /$ năm đến $2000 \mathrm{~mm} /$ năm đạt 11786,77 ha chiếm $32,05 \%$, các giá trị NDVI tăng từ 0,1 đến 0,6 . Diện tích giảm dần từ lượng mưa trung bình năm $1920 \mathrm{~mm} /$ năm đến $2000 \mathrm{~mm} /$ năm. Với giá trị $\mathrm{NDVI}=0,62$ có diện tích là thấp nhất 1,79 ha chiếm $0,0049 \%$.

Qua đó có thể thấy nước là yếu tố chính liên quan đến sinh trưởng phát triển của thực vật và tác động đến các tính chất đất dẫn đến thay đổi tính chất đất dốc. 
D.X.Van et al./No.06_September 2017|p.50-54

Bảng 1: Thống kê diện tích đất theo NDVI và lương mưa trung bình năm huyện Phú Luơng Đon vị (ha)

\begin{tabular}{|c|c|c|c|c|c|c|c|c|c|}
\hline LM & 1750 & 1800 & 1820 & 1880 & 1920 & 1950 & 2000 & $\begin{array}{l}\text { Tỷ } \\
\text { lệ(\%) }\end{array}$ & Tổng \\
\hline 0,1 & 36,83 & 62,65 & 145,40 & 675,31 & 159,58 & 114,46 & 57,02 & 3,40 & 1251,26 \\
\hline 0,2 & 209,65 & 335,57 & 567,84 & 1703,81 & 777,10 & 551,71 & 116,99 & 11,59 & 4262,66 \\
\hline 0,3 & 434,92 & 549,53 & 1076,46 & 2187,79 & 1333,86 & 819,36 & 133,47 & 17,77 & 6535,39 \\
\hline 0,6 & 3116,56 & 2749,89 & 3749,12 & 7387,83 & 4561,33 & 2773,71 & 388,22 & 67,23 & 24726,66 \\
\hline 0,62 & 1,48 & 0,12 & 0,18 & 0,0 & 0,0 & 0,0 & 0,0 & 0,0049 & 1,79 \\
\hline Tỷ lệ(\%) & 10,33 & 10,05 & 15,06 & 32,51 & 18,58 & 11,58 & 1,89 & 100 & \\
\hline Tổng & 3799,44 & 3697,77 & 5539,00 & 11954,73 & 6831,87 & 4259,25 & 695,70 & & 36777,76 \\
\hline
\end{tabular}

Phân loại NDVI theo chất lương thực vật trong lớp phủ bền mặt đất

\begin{tabular}{|c|c|}
\hline Giá trị NDVI & Lớp phủ bề mặt đất \\
\hline$>0,1$ & Khu vưc cẵn cỗi của đá; cát; mặt nước; bê tông \\
\hline $0,1-0,2$ & Đất đá cằn cỗi, cây bụi \\
\hline $0,2-0,3$ & Cây bui và trảng có; đất nông nghiẹp để trống \\
\hline $0,3-0,6$ & Trảng có, cây trồng nông nghiệp, rùng thua \\
\hline$>0,6$ & Rùng nhiệt đới \\
\hline
\end{tabular}

Bảng 2: Thống kê diện tích đất theo chỉ số NDVI và độ dốc huyện Phú Luơng

Đo'n vị (ha)

\begin{tabular}{llllllll}
$\begin{array}{l}\text { NDDW } \\
\text { Độ dốc }\end{array}$ & 0,1 & 0,2 & 0,3 & 0,6 & 0,62 & Tỷ lệ(\%) & Tổng \\
\hline$<3^{0}$ & 114,32 & 386,12 & 550,71 & 1879,88 & 0,09 & 7,97 & 2931,12 \\
$3^{0}-8^{0}$ & 457,23 & 1488,98 & 2265,35 & 7967,59 & 0,19 & 33,12 & 12179,34 \\
$8^{0}-15^{0}$ & 402,23 & 1379,75 & 2093,64 & 7792,78 & 0,38 & 31,73 & 11668,79 \\
$15^{0}-20^{0}$ & 147,90 & 493,82 & 774,50 & 3047,19 & 0,43 & 12,14 & 4463,83 \\
$20^{0}-25^{0}$ & 85,35 & 286,06 & 462,59 & 1906,05 & 0,37 & 7,45 & 2740,42 \\
$>25^{0}$ & 65,83 & 270,27 & 458,79 & 1997,52 & 0,47 & 7,59 & 2792,88 \\
\hline Tỷ lệ(\%) & 3,46 & 11,71 & 17,96 & 66,87 & 0,0052 & 100 & \\
Tổng & 1272,86 & 4305,01 & 6605,58 & 24591,01 & 1,93 & $\mathbf{3 6 7 7 6 , 3 8}$ \\
\hline
\end{tabular}

3.2.2. Tác động giữa chỉ số thực vật (NDVI) và độ dốc tại huyện Phú Lương (Bảng 2)

Qua hình 1 và bảng 2 cho thấy: tại khu vực có giá trị $\mathrm{NDVI}=0,62$ có diện tích thấp nhất với 1,93 ha chiếm $0,0052 \%$ tập trung chủ yếu ở độ dốc từ $15^{\circ}$ đến $>25^{\circ}$, giá trị $\mathrm{NDVI}=0,6$ có diện tích cao nhất là 24591,01 ha chiếm $66,87 \%$ tập trung ở cả tất cả độ dốc, nhiều nhất tại dộ dốc $3^{0}-8^{0}$ có diện tích 7967,59 ha trên diện tích 12179,34 ha $(33,12 \%)$. Ngoài ra ở độ dốc từ $<3^{0}$ đến $15^{\circ}$ các giá trị NDVI có diện tích tăng dần, từ độ dốc $15^{\circ}$ đến $>25^{\circ}$ các giá trị NDVI lại có diện tích giảm dần.

Căn cứ vào đó có thể chỉ ra tại mỗi độ dốc tồn tại các thực vật khác nhau và khả năng cải tạo tác động đến môi trường đất khác nhau.

\subsection{Phân tích đối tượng tác động là con người theo mục đích sử dụng}

Tổng diện tích tự nhiên của huyện Phú Lương năm 2014 là 36761,7 ha, trong đó: Đất nông nghiệp có 31141,5 ha chiếm 84,7\%, đất phi nông nghiệp có5344,2 ha chiếm $14,5 \%$, đất chưa sử dụng có 276,0 ha chiếm $0,8 \%$. Chính vì mục đích sử dụng đất, nên con người đã tác động vào tính chất đất thông qua các công cụ, khai thác, cùng với đó là việc chăm bón các loại cây trồng như đất lúa diện tích 3873,4 ha chiếm $10,5 \%$, đất trồng cây hàng năm khác 1865,4 ha chiếm 5,1\%; đất trồng cây lâu năm 7324,0 ha chiếm 19,9\%. Đất rừng sản xuất diện tích 15803,0 ha chiếm $42,99 \%$ (chủ yếu là cây keo và bạch đàn) đất rừng phòng hộ 662,64 ha chiếm 1,80\%.

\subsubsection{Phân tích một số tính chất đất theo độ dốc với chỉ số thục vật (NDVI) (Bảng 3)}

Hàm lượng $\mathrm{pH}$ ở mức chua nhiều đên chua vừa $(4,04$ đến 5,5$)$. Hàm lượng đạm tổng số giao động trong mức thấp và trung bình. Hàm lượng mùn tổng số đều giảm dần từ độ dốc $20^{0}-25^{0}$ là $2,15 \%$, ở mức độ trung bình, độ dốc $15^{0}-20^{0}$ là $1,97 \%$, ở mức thấp; độ dốc $8^{0}-15^{0}$ là $0,65 \%$, ở mức rất thấp. Hàm lượng $\mathrm{K}_{2} \mathrm{O}$ dễ tiêu đều ở mức độ thấp. Hàm lượng $\mathrm{P}_{2} \mathrm{O}_{5}$ dễ tiêuđều ở mức rất nghèo. Hàm lượng $\mathrm{Ca}^{2+}$ trao đổi trong đất trong khoảng thấp. Hàm lượng $\mathrm{Mg}^{2+}$, trao đổi trong đất trong khoảng rất thấp đến thấp, cao nhất là độ dốc $8^{0}-15^{0}$ và $20^{0}-25^{0}$, đều đạt $0,92(\mathrm{meq} / 100 \mathrm{~g})$ ở mức thấp, độ dốc $15^{0}-20^{0}$ được 0,33 (meq/100g) ở mức rất thấp.

- Về phần đất dốc lấy ở nơi có lớp phủ thực vật là rùng Keo non mói trồng: 
Hàm lượng $\mathrm{pH}$ giao động từ 4,39 đến 5,57 , ở mức chua nhiều đến chua vừa. Hàm lượng đạm tổng số ở mức trung bình. Hàm lượng mùn tổng số ở độ dốc $20^{0}-25^{0}$ là $2,17 \%$, mức độ trung bình; độ dốc $15^{0}-20^{0}$ là $0,85 \%$, ở mức rất thấp; độ dốc $8^{0}-15^{0}$ là $1,98 \%$, ở mức thấp. Hàm lượng $\mathrm{K}_{2} \mathrm{O}$ dễ tiêu ở mức độ thấp. Hàm lượng $\mathrm{P}_{2} \mathrm{O}_{5}$ dễ tiêu ở mức rất nghèo đến nghèo; ở độ dốc $8^{0}-15^{0} \mathrm{là} 6,43(\mathrm{mg} / 100 \mathrm{~g})$, ở mức nghèo, độ dốc $15^{\circ}-20^{\circ}$ đến độ dốc $20^{\circ}-25^{\circ}$, lần lượt $2,44(\mathrm{mg} / 100 \mathrm{~g})$ và $4,43(\mathrm{mg} / 100 \mathrm{~g})$, ở mức rất nghèo. Hàm lượng $\mathrm{Ca}^{2+}$, trao đổi trong đất trong khoảng thấp, đến trung bình, cao nhất là độ dốc $8^{0}-15^{0}$, là $5,97(\mathrm{meq} / 100 \mathrm{~g})$, mức nghèo; ở hai độ dốc $15^{0}-20^{0}$ đến $20^{0}-25^{0}$ lần lượt đạt 2,68 , $2,31(\mathrm{meq} / 100 \mathrm{~g})$. Hàm lượng $\mathrm{Mg}^{2+}$, trao đổi trong đất trong khoảng rất thấp đến thấp, cao nhất là độ dốc $8^{0}-15^{0}$, đến $15^{0}-$ $20^{0}$ lần lượt được $0,80(\mathrm{meq} / 100 \mathrm{~g})$ đến $0,82(\mathrm{meq} / 100 \mathrm{~g})$, ở mức thấp; độ dốc $20^{0}-25^{0}$ được $0,39(\mathrm{meq} / 100 \mathrm{~g})$, ở mức rất thấp.

- Về phần đất dốc lấy ở noi có trên lóp phủ thực vật là rùng Keo lâu năm:

Hàm lượng $\mathrm{pH}$ giao động trong khoảng từ 4,25 đến 5,39 , trong khoảng chua đến chua vừa. Hàm lượng đạm tổng số, ở mức trung bình. Hàm lượng mùn tổng số, ở mức thấp đến trung bình, ở mức trung bình, gồm độ dốc $8^{0}-15^{0}$ là $2,45 \%$, tiếp theo là độ dốc $20^{\circ}-25^{\circ}$, là $2,28 \%$, độ dốc $8^{0}$ $15^{0}$ là $1,78 \%$, ở mức thấp. Hàm lượng $\mathrm{K}_{2} \mathrm{O}$ dễ tiêu ở mức độ thấp. Hàm lượng $\mathrm{P}_{2} \mathrm{O}_{5}$ dễ tiêu, ở mức rất nghèo đến nghèo, ở độ dốc $20^{\circ}-25^{0}$ xuống độ dốc $15^{0}-20^{\circ}$ lần lượt 6,24 $(\mathrm{mg} / 100 \mathrm{~g}), 6,23(\mathrm{mg} / 100 \mathrm{~g})$, ở mức nghèo, ở độ dốc $8^{0}-15^{0}$ còn $3,15(\mathrm{mg} / 100 \mathrm{~g})$, ở mức rất nghèo. Hàm lượng $\mathrm{Ca}^{2+}$, trao đổi trong đất trong khoảng thấp, đến trung bình, cao nhất là độ dốc $15^{0}-20^{\circ}$, đến độ dốc $20^{\circ}-25^{0}$ lần lượt đạt 5,97 (meq/100g), 5,78 (meq/100g), ở mức trung bình; ở độ dốc $8^{0}-15^{0}$ đạt $2,68(\mathrm{meq} / 100 \mathrm{~g})$ ở mức rất thấp. Hàm lượng $\mathrm{Mg}^{2+}$ trao đổi trong đất trong khoảng thấp.

\subsubsection{Phân tích một số chỉ tiêu về kim loại nặng và hóa chất BVTV (Bảng 4)}

- Đối với đất trồng chè: được trồng tập trung từ độ dốc $3^{0}-15^{0}$, hàm lượng $\mathrm{pH}$ từ 4,79 đến 5,33 trong khoảng chua vừa. Hàm lượng kim loại nặng $(\mathrm{As}, \mathrm{Pb}$, Cd) đều thấp hơn QCVN 03-MT.ở độ dốc $3^{0}-8^{0}$ luôn cao hơn độ dốc $8^{0}-15^{0}$.Do việc chăm sóc về bón phân, sử dụng thuốc bảo vệ thực vật tại các sườn dốc này tập trung chủ yếu ở độ dốc $3^{0}-8^{0}$, cho nên tính chất môi trường đất ở đây cao hơn độ dốc $8^{0}-15^{0}$.

Bảng 3: Kết quả phân tích tính chất đất tại các độ dốc với chỉ số thưc vật (NDVI)

\begin{tabular}{|c|c|c|c|c|c|c|c|c|}
\hline $\begin{array}{c}\text { Địa điểm } \\
\text { lấy }\end{array}$ & Độ dốc & pH & $\begin{array}{c}\text { Đạm ts } \\
(\mathrm{mg} / \mathrm{g})\end{array}$ & $\begin{array}{l}\text { Mùn ts } \\
\text { (\%OM) }\end{array}$ & $\begin{array}{c}\mathrm{K}_{2} \mathrm{O} \mathrm{dt} \\
(\mathrm{mg} / \mathrm{kg})\end{array}$ & $\begin{array}{c}\mathrm{P}_{2} \mathrm{O}_{5} \mathrm{dt} \\
(\mathrm{mg} / 100 \mathrm{~g}) \\
\end{array}$ & $\begin{array}{c}\mathrm{Ca}^{2+} \\
(\mathrm{meq} / \mathbf{1 0 0 g})\end{array}$ & $\begin{array}{c}\mathrm{Mg}^{2+} \\
(\mathrm{meq} / \mathrm{100g}) \\
\end{array}$ \\
\hline \multirow{3}{*}{ Động Đạt } & $8^{0}-15^{0}$ & 5,50 & 1,20 & 0,65 & 47,42 & 2,41 & 3,58 & 0,92 \\
\hline & $15^{0}-20^{0}$ & 4,04 & 1,49 & 1,97 & 39,06 & 4,03 & 2,21 & 0,33 \\
\hline & $20^{0}-25^{0}$ & 4,15 & 2,04 & 2,15 & 49,04 & 3,05 & 2,68 & 0,92 \\
\hline \multirow{3}{*}{ Yên Lạc } & $8^{0}-15^{0}$ & 5,29 & 1,52 & 1,98 & 54,15 & 6,43 & 5,97 & 0,80 \\
\hline & $15^{0}-20^{0}$ & 5,57 & 1,26 & 0,85 & 47,92 & 2,44 & 2,68 & 0,82 \\
\hline & $20^{0}-25^{0}$ & 4,39 & 1,59 & 2,17 & 38,06 & 4,43 & 2,31 & 0,39 \\
\hline \multirow{3}{*}{ Yên Ninh } & $8^{0}-15^{0}$ & 4,25 & 2,64 & 2,45 & 49,14 & 3,15 & 2,68 & 0,95 \\
\hline & $15^{0}-20^{0}$ & 5,39 & 1,82 & 1,78 & 53,16 & 6,23 & 5,97 & 0,83 \\
\hline & $20^{0}-25^{0}$ & 5,11 & 2,01 & 2,28 & 54,12 & 6,24 & 5,78 & 0,87 \\
\hline
\end{tabular}

Chú ý:

Động Đạt: Đất lấy ở độ dốc và lớp phủ thực vật chủ yếu cây bụi;

Yên Lac: Đất lấy trên lớp phủ thực vật là rù̀ng Keo non mó́i trồng;

Yên Ninh: Đất lấy trên lớp phủ thực vật là rùng Keo lâu năm.

- Về phần đất dốc lấy ở nơi có lóp phủ thục vật chủ yếu là cây bụi:

Bảng 4: Kết quả phân tích một số chỉ tiêu về kim loại nặng trong đất và hóa chất BVTV

\begin{tabular}{lllllll}
\hline \multicolumn{1}{c}{ Mẫu đất } & \multicolumn{1}{c}{ Độ dốc } & $\begin{array}{c}\mathbf{A s} \\
(\mathbf{m g} / \mathbf{k g})\end{array}$ & $\begin{array}{c}\mathbf{P b} \\
(\mathbf{m g} / \mathbf{k g})\end{array}$ & $\begin{array}{c}\mathbf{C d} \\
(\mathbf{m g} / \mathbf{k g})\end{array}$ & $\mathbf{p H}_{\mathbf{K C l}}$ & Hóa chất BVTV \\
\hline \multirow{2}{*}{ Chè } & $3^{0}-8^{0}$ & 5,44 & 23,78 & 0,41 & 4,79 & Không phát hiện \\
\hdashline Lúa & $8^{0}-15^{0}$ & 4,33 & 19,45 & 0,28 & 5,33 & Không phát hiện \\
\hdashline Keo & $<3^{0}$ & 6,03 & 29,13 & 0,69 & 5,21 & Không phát hiện \\
\hline \multirow{2}{*}{ QCVN 03-MT } & $3^{0}-8^{0}$ & 5,52 & 22,37 & 0,34 & 5,19 & Không phát hiện \\
& $15^{0}-20^{0^{\prime}}$ & 4,26 & 16,04 & 0,23 & 4,84 & Không phát hiện \\
\hline
\end{tabular}


- Đối với đất trồng lúa: mẫu được lấy theo sườn độ dốc từ $0^{0}-8^{0}, \mathrm{pH}$ trong khoảng chua vừa 5,21 và 5,19 . Hàm lượng kim loại nặng $(\mathrm{As}, \mathrm{Pb}, \mathrm{Cd})$ đều thấp hơn QCVN/03-MT. Hàm lượng As ở độ dốc $<3^{0}$ đạt $6,03(\mathrm{mg} / \mathrm{kg})$, cao hơn độ đốc $3^{0}-8^{0}$. Hàm lượng $\mathrm{Pb}$ ở độ dốc $<3^{0}$ đạt 29,13(mg/kg), trong khi độ dốc $3^{0}-8^{0}$ chỉ đạt $22,37(\mathrm{mg} / \mathrm{kg}), \mathrm{Cd}$ ở độ dốc $<3^{0}$ cao hơn gấp 2 lần độ dốc $3^{0}-8^{0}$ từ $0,69(\mathrm{mg} / \mathrm{kg})$ xuống còn $0,34(\mathrm{mg} / \mathrm{kg})$.

- Đối với đất trồng Keo: Hàm lượng $\mathrm{pH}=4,84$ ở mức chua vừa. Hàm lượng kim loại nặng $(\mathrm{As}, \mathrm{Pb}, \mathrm{Cd})$ đều thấp hơn đất lúa, đất trồng chè do ít tác động về phương diện sử dụng phân bón, thuốc trừ sâu so với đất trồng lúa và đất trồng chè.

Về hàm lượng hóa chất bảo vệ thực vật của 3 loại đất trồng lúa, chè và keo đều không phát hiện thấy.

\section{Kết luận}

- Tính chất, môi trường đất luôn bị chi phối và tác động của 2 yếu tố, đó là tài nguyên sinh khí hậu và con người.

- Đất dốc lấy ở nơ có lóp phủ thực vật chủ yếu là cây buii: Tính chất đất ở mức chua vừa, hàm lượng đạm tổng số giao động trong mức thấp và trung bình, hàm lượng mùn tổng số ở mức trung bình và mức rất thấp, hàm lượng $\mathrm{K}_{2} \mathrm{O}$ dễ tiêu đều ở mức độ thấp, hàm lượng $\mathrm{P}_{2} \mathrm{O}_{5}$ dễ tiêuở mức rất nghèo, hàm lượng cation kiềm trao đổi trong đất $\left(\mathrm{Ca}^{2+}, \mathrm{Mg}^{2+}\right)$ trong khoảng rất thấp đến thấp.

- Đất dốc lấy ở nơ có lớp phủ thực vật là rù̀ng keo non mói trồng: Tình chất đất ở mức chua nhiều đến chua vừa, hàm lượng đạm tổng số, mùn tổng số ở mức thấp đến mức trung bình, hàm lượng $\mathrm{K}_{2} \mathrm{O}$ dễ tiêu đều ở mức độ thấp, hàm lượng $\mathrm{P}_{2} \mathrm{O}_{5}$ dễ tiêu, ở mức rất nghèo đến nghèo, hàm lượng $\mathrm{Ca}^{2+}$, trao đổi trong đất trong khoảng thấp đến trung bình. Hàm lượng $\mathrm{Mg}^{2+}$ trao đổi trong đất trong khoảng rất thấp đến thấp.
- Đất dốc lấy ở noi có trên lớp phủ thực vật là rù̀ng keo lâu năm: Tính chất đất thể hiện chua đến chua vừa, hàm lượng đạm tổng số ở mức trung bình đến cao, hàm lượng mùn tổng số ở mức thấp đến trung bình, hàm lượng $\mathrm{K}_{2} \mathrm{O}$ dễ tiêu đều ở mức độ thấp, hàm lượng $\mathrm{P}_{2} \mathrm{O}_{5}$ dễ tiêu ở mức rất nghèo đến nghèo, hàm lượng $\mathrm{Ca}^{2+}$, trao đổi trong đất trong khoảng thấp đến trung bình, hàm lượng $\mathrm{Mg}^{2+}$, trao đổi trong đất trong khoảng thấp.

- Hàm lượng kim loại nặng đều thấp hơn QCVN/03MT quy định giới hạn kim loại nặng trong đất nông nghiệp. Tuy nhiên, những cây trồng mà còn người chăm sóc thường xuyên như lúa, chè thì có hàm lượng kim loại nặng trong đất cao hơn so với đất trồng keo. Với các độ dốc khác nhau thì hàm lượng kim loại nặng khác nhau.

- Hóa chất bảo vệ thực vật trong 3 loại đất trồng lúa, chè và keo đều không phát hiện thấy.

\section{TÀI LIỆU THAM KHẢO}

1. Lê Thị Thu Hiền (2013). Áp dụng chỉ số thực vật (NDVI) của ảnh landsat đánh giá hoang mạc hóa tỉnh Bình Thuận, Tạp chí các Khoa học về Trái đất;

2. Đỗ Thị Vân Hương (2014).Nghiên cưu, đánh giá tài nguyên sinh khi hậu vùng Đông Bắc Việt Nam cho phát triển một số cây trồng nông, lâm nghiệp có giá trị kinh tế, Luận án Tiến sỹ chuyên ngành, địa lý Tài nguyên và Môi trường, Viện Hàn lâm Khoa học và Công nghệ Việt Nam;

3. Nguyễn Công Vinh, Mai Thị Lan Anh (2011), Quản lý và sư dụng đất dốc bền vũng ở việt nam, Nxb Đại Học Quốc Gia Hà Nội;

4. Wanli Huang, Beicheng Xia, Zhimin Zeng, Guangfa Lin (2008), The Relationship between NDVI, Stand Age and Terrain Factors of Pinus elliottii Forest", ISBN:pp.232-236. 